\title{
General Design Approach for High Process Stability of Metal Cutting Machinery
}

\author{
Gerhard Kehl \\ University of Applied Sciences \\ Flandernstr. 101, 73732 Esslingen, Germany \\ gerhard.kehl@hs-esslingen.de
}

\section{Extended Abstract}

A central field of activity in the development of new machine tools before their launch into market are the cutting process stability and the work piece surface quality. Already during the design process some machine tool manufacturers apply simulation on digital models to investigate the expected process stability and the achievable cutting depth. For this purpose, the focus is on the dynamic characteristics of the overall machining system (consisting of machine tool + cutting tool + fixture + work piece) and the operation under the influence of control technology [1].

Resulting from dynamic wave-on-wave cutting due to oscillation regenerative chatter plays the key role in mechanisms limiting the productivity and leading to non-recallable portion of installed cutting performance. As a consequence the design goal is to noticeably expand the stable cutting area in stability charts of reference cutting processes [2].

Recently the integration of cutting process models into the machine tool finite element (FE) model allows to compare alternative conceptual variants. For this purpose linear analytical models for turning and milling have been implemented for use in the software ANSYS [3] and PERMAS. Extensive cutting tests have been realized to attain sufficient data on cutting force coefficients and suitable stability criteria. Finally the transient chip-thickness modulation due to spatial relative movement between tool and work piece has been implemented as criterion in FE user macros.

To gain all data for a complete stability chart of a specific milling process unfortunately three loops with basically transient sub-simulations have to be conducted (tool rotation increments, different cutting depths, different spindle speeds). In spite of model-reduction the effort to gain useful results is too time-consuming for industrial design processes, because lots of custom applications, tools, work pieces etc. have to be taken into account.

\section{Results and Conclusions}

Instead of the scientific aspiration to simulate as accurate as possible, a general method has been implemented based on Tlusty's law [4]. In this method the spacial negative real part of the relative compliance between tool and work piece is the representation for the dynamic characteristics of the overall machining system. This data can be gained rapidly from the FE analysis results and can be interpreted as a pragmatic criterion to evaluate the tendency of cutting processes to chatter.

Because of its economic viability regarding simulation costs and its results in many successful machine designs this method has entered the design process of a few german machine tool manufacturers. Hence machine designs can be evaluated before manufacturing any part of a new machine. Furthermore it supplies novel opportunities to reach the machine tool users expectations in productivity, tool lifetime and surface quality of work pieces.

\section{References}

[1] G. Kehl and D. Blank, "Finite Element Analysis Simulation of Machine Tools with Integrated Drive Control," in Proceedings of the 8th International Conference on Finite Differences, Finite Elements, Finite Volumes, Boundary Elements (F-and-B '15), Rome, pp. 13-16, 2015.

[2] Y. Altintas and M. Weck, "Chatter Stability of Metal Cutting and Grinding," Annals of CIRP, Key Note Paper of STCM, vol. 53, no. 2, pp. 619-642, 2004.

[3] E. Rudnyi and R. Rauch, "System Level Simulation with Simplorer and ANSYS: Through Simulation to Stable Productional Process," in Proceedings of the IWF-Symposium: Simulation von Werkzeugmaschinen, Zürich, 2010.

[4] O. Danek, M. Polacek, J. Spacek and J. Tlusty, Selbsterregte Schwingungen and Werkzeugmaschinen. VEB Technik Berlin, 1962. 